\title{
Deamidation reactions of protonated asparagine and glutamine investigated by ion spectroscopy
}

\author{
Lisanne J.M. Kempkes ${ }^{1}$, Jonathan K. Martens ${ }^{1}$, Josipa Grzetic ${ }^{1}$, Giel Berden ${ }^{1}$, Jos Oomens ${ }^{1,2, *}$ \\ ${ }^{1}$ Radboud University, Institute for Molecules and Materials, FELIX Laboratory, Toernooiveld 7c, \\ 6525 ED Nijmegen, The Netherlands
}

${ }^{2}$ Van 't Hoff Institute for Molecular Sciences, University of Amsterdam, Science Park 904, 1098 XH Amsterdam, the Netherlands

RATIONALE: Deamidation of Asn and Gln residues is a primary route for spontaneous posttranslational protein modification. Various structures have been proposed for the deamidation products of the protonated amino acids. Here we verify these structures by ion spectroscopy, as well as the structures of parallel and sequential fragmentation products.

METHODS: Infrared ion spectroscopy using the free electron laser FELIX has been applied to the reaction products from deamidation of protonated glutamine and asparagine in a tandem mass spectrometer. IR spectra were recorded over the $800-1900 \mathrm{~cm}^{-1}$ spectral range by infrared multiple-photon dissociation (IRMPD) spectroscopy. Molecular structures of the fragment ions are derived from comparison of the experimental spectra with spectra predicted for different candidate structures by density functional theory (DFT) calculations.

RESULTS: $\left[\mathrm{AsnH}^{+}-\mathrm{NH}_{3}\right]^{+}$is found to possess a 3-amino succinic anhydride structure protonated on the amino group. The dissociation reaction involving loss of $\mathrm{H}_{2} \mathrm{O}$ and $\mathrm{CO}$ forms a linear immonium ion. For $\left[\mathrm{GlnH}^{+}-\mathrm{NH}_{3}\right]^{+}$, the $\mathrm{N}$-terminal nitrogen acts as the nucleophile leading to an oxo-proline product ion structure. For $\left[\mathrm{GlnH}^{+}-\mathrm{NH}_{3}\right]^{+}$a sequential loss of $\left[\mathrm{CO}+\mathrm{H}_{2} \mathrm{O}\right.$ ] is found, leading to a pyrolidone-like structure. We also confirm by IR spectroscopy that dehydration of protonated aspartic acid $\left(\mathrm{AspH}^{+}\right)$and glutamic acid $\left(\mathrm{GluH}^{+}\right)$leads to identical structures as to those found for the loss of $\mathrm{NH}_{3}$ from $\mathrm{AsnH}^{+}$and $\mathrm{GlnH}^{+}$. 
CONCLUSIONS: The structure determined for $\mathrm{AsnH}^{+}$is in agreement with the suggested structure derived from measured and computed activation energies. Infrared ion spectra for the $\mathrm{NH}_{3}$-loss product from $\mathrm{GlnH}^{+}$establish that a different reaction mechanism occurs for this species as compared to $\mathrm{AsnH}^{+}$. For both amino acids, loss of $\mathrm{NH}_{3}$ occurs from the side-chain.

*Corresponding author: joso@science.ru.nl

\section{Introduction}

The amino acids glutamine ( $G \ln , Q$ ) and asparagine (Asn, $N)$ feature an amide group in their side chain. Deamidation of Asn and Gln residues is a primary route for spontaneous posttranslational protein modification. [1] It is a dominant pathway for protein degradation and is a $\mathrm{pH}$ dependent process. Peptides with glutamine as the N-terminal amino acid are known to undergo partial deamidation in solution, which converts the terminal glutamine residue into the cyclic pyroglutamyl residue (2-pyrrolidone-5-carboxylic acid). [2,3] Structural changes of the protein upon such reactions induce biological responses such as molecular clocks for the timing of biological processes or acceleration of amyloid aggregate formation (pathological protein formation). [4,5] Robinson et al. [5] strengthen the hypothesis that glutaminyl and asparaginyl residues in peptides serve, through deamidative transformation into glutamyl and aspartyl residues, as molecular timers of biological events such as protein development and aging. Amides may serve as molecular indicators that the integrity of each protein molecule has been maintained. [5] This fact can be used to investigate for the presence of post translational modifications.

A variety of studies have addressed the deamidation reactions of protonated GIn and Asn containing proteins and peptides in a mass spectrometer, where the reactions are initiated by collisional activation, occur in the gas phase, and can be analyzed in terms of the mass to charge ratio of the resulting fragments [1,3,6,12-19,31,32]. In order to gain detailed mechanistic insight into these reactions, the deamidation of protonated Asn and GIn has been studied using a variety of methods including energy-dependent collision-induced dissociation, 
deuterium exchange, and threshold collision induced dissociation (TCID) combined with theoretical investigations at various levels of theory.

While there is a general agreement that the thermodynamically most favored site of protonation of GIn and Asn is the $\alpha$-amino group [6,7], collisional activation can mobilize the additional proton [8-10], so that elimination of $\mathrm{NH}_{3}$ can conceivably occur from either the $\mathrm{N}$ terminal amine or from the side-chain amide group. The latter option has been assumed in the majority of earlier studies [11] as it leads to an acylium ion structure - either as the final or intermediate product - rather than a presumably less stable $\alpha$-carbocation. Although some studies suggest linear acylium-type product ions, most studies propose $\mathrm{NH}_{3}$ loss to occur concomitantly with a nucleophilic attack onto the acylium or carbocation center by one of the nucleophiles in the molecule, leading to cyclic product ion structures. Schemes $1 \mathrm{~A}$ and $1 \mathrm{~B}$ outline the various possibilities for the formation of cyclic structures by deamidation of protonated Asn and GIn, respectively. For each of the conceivable product ion structures, several protonation sites are possible and further increase the diversity of the deamidation chemistry.

For $\mathrm{AsnH}^{+}$, Heaton and Armentrout [12] used TCID to obtain values for the activation energies of the various dissociation pathways, which were compared with detailed high-level computations of the potential energy surface. The study presented here confirms that $\mathrm{NH}_{3}$ loss occurs from the amide side chain of the molecule as a result of nucleophilic attack by the Cterminal carbonyl oxygen and leads to a product ion having a succinic anhydride structure (see Scheme 1A). Other dissociation reactions, in particular the parallel reaction involving $\mathrm{H}_{2} \mathrm{O}+\mathrm{CO}$ loss from the C-terminus are also investigated here and will be addressed further below.

For $\mathrm{GlnH}^{+}$, the situation is less well understood; there is not an in depth study of the glutamine potential energy surface including transition-states and intermediate reaction species available. A reaction mechanism analogous to that identified for $\mathrm{AsnH}^{+}$would lead to a six-membered glutaric anhydride structure. In contrast to $\mathrm{AsnH}^{+}$, however, the alternative mechanisms outlined in Scheme 1B lead to energetically more favorable five-membered ring structures. Table 1 outlines the free energy differences between these four-five and six-membered ring 
structures and their different protonation sites. Earlier studies [4, 13-15] have indeed proposed such five-membered structures, in particular the oxo-proline structure (pyroglutamic acid). Further insights into the dissociation mechanisms may also be obtained from studies of the $\mathrm{H}_{2} \mathrm{O}$ loss reaction of protonated glutamic acid $\left(\mathrm{GluH}^{+}\right)$, which have often been suggested to lead to the same product ions.

Recently it has been identified that residue specific fragmentation of protonated peptides containing glutamine or asparagine leading to succinimide and glutarimide structures, occurs $[16,17]$ instead of the more standard formation of $b_{2}$ ions. [18] It was found that dissociation occurs via a nucleophilic attack of the side chain amide nitrogen atom of Asn and Gln on the adjacent peptide carbonyl carbon.

Ion spectroscopy is a proven tool for establishing the molecular structure of gas-phase amino acid ions [19], their (de)protonation site [20-22], and the structure of their gas-phase reaction products in CID MS/MS [23]. Here, the fragmentation reactions after CID of $\mathrm{AsnH}^{+}$and $\mathrm{GlnH}^{+}$ are investigated using ion spectroscopy. Computed spectra for previously suggested isomers $[12,13]$ are therefore compared with the measured IRMPD spectrum.

Using the product ion structures we are able to propose fragmentation reaction mechanisms for deamidation of $\mathrm{AsnH}^{+}$and $\mathrm{GlnH}^{+}$. These results confirm that $\mathrm{AsnH}^{+}$and $\mathrm{GlnH}^{+}$indeed follow different fragmentation pathways. 


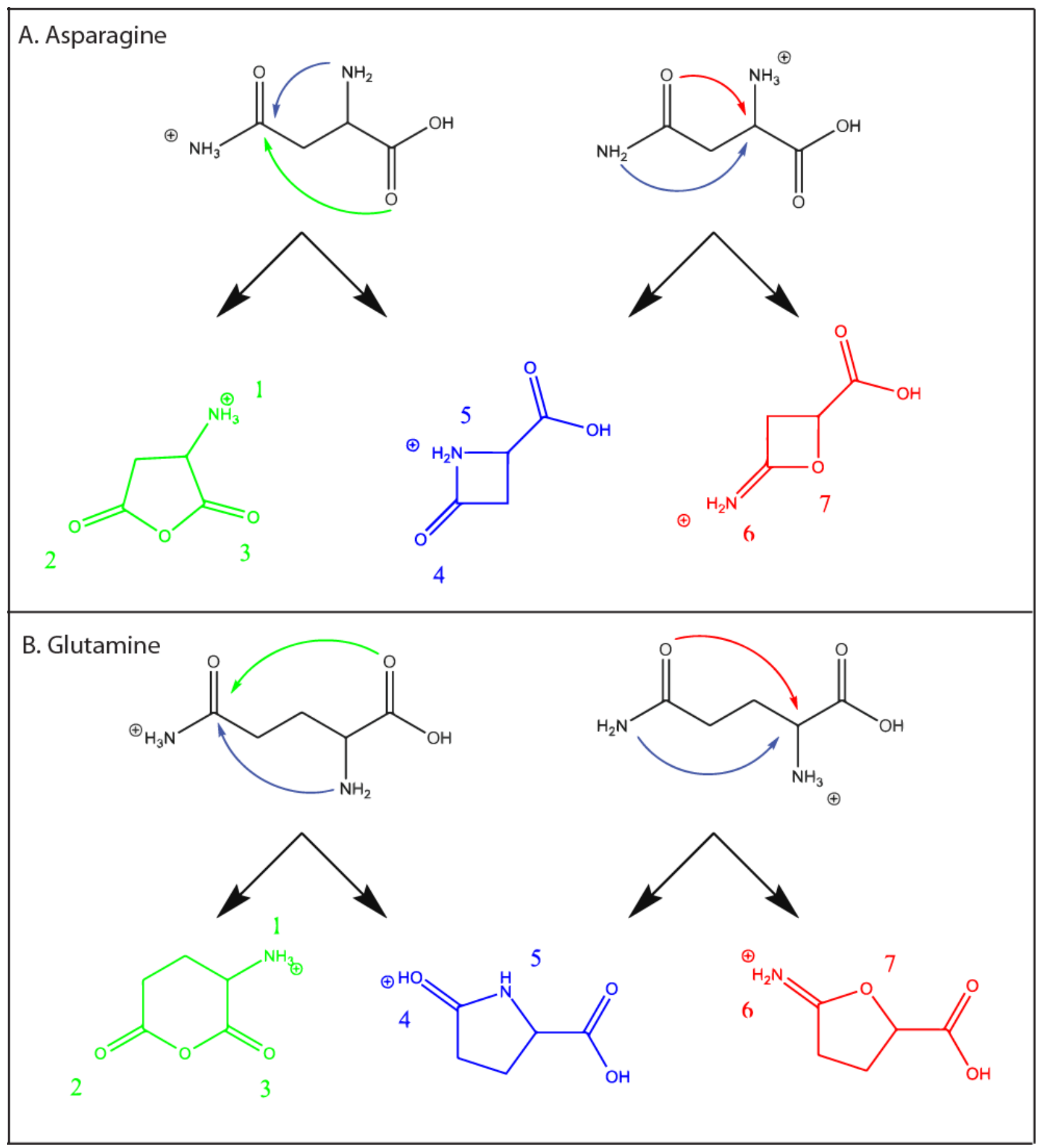


Scheme 1: A. Conceivable reaction mechanisms for the loss of $\mathrm{NH}_{3}$ from the side chain (blue and green) or from the N-terminus (red and blue) of $\mathrm{AsnH}^{+}$. The numbers in the figure indicate the protonation site and correspond with the energies in table 1. B. Conceivable reaction pathways for loss of $\mathrm{NH}_{3}$ from $\mathrm{GnH}^{+}$. $\mathrm{NH}_{3}$ can be expelled from the $\mathrm{N}$-terminus or from the side-chain amide. Note that loss from the N-terminus by cyclization through the side-chain nitrogen and loss from the side chain by cyclization through the $N$-terminal nitrogen lead to the same oxoproline product ion structure. The numbers in the figure indicate the protonation site and correspond with the numbers in Table 1.

\begin{tabular}{|l|l|l|}
\hline Number & $\mathrm{AsnH}^{+}-\mathrm{NH}_{3}(\mathrm{~kJ} / \mathrm{mol})$ & $\mathrm{GlnH}^{+}-\mathrm{NH}_{3}(\mathrm{~kJ} / \mathrm{mol})$ \\
\hline 1 & 0 & +61 \\
\hline 2 & +59 & +100 \\
\hline 3 & +35 & +92 \\
\hline 4 & +26 & 0 \\
\hline 5 & +32 & +29 \\
\hline 6 & +64 & +11 \\
\hline 7 & +188 & +180 \\
\hline
\end{tabular}

Table 1. Calculated relative free energies at the $M P 2(f u l l) / 6-311+G(2 d, 2 p) / / B 3 L Y P / 6-31++G(d, p)$ level at $298 \mathrm{~K}$ for the different possible structures after $\mathrm{NH}_{3}$ loss. The numbers refer to the different structures in Scheme 1.

\section{Experimental and computational methods}

\subsection{IRMPD Spectroscopy}

Infrared spectra of the protonated amino acids and their CID product ions were obtained by infrared multiple-photon dissociation (IRMPD) [24-26] spectroscopy using a Fourier Transform Ion Cyclotron Resonance mass spectrometer (FTICR-MS) as well as a modified 3D quadrupole ion trap MS (Bruker, AmaZon Speed ETD), both coupled to the beam line of the infrared free electron laser FELIX. [25] All samples were purchased from Sigma Aldrich (Zwijndrecht, The Netherlands) and used without further purification. 
For experiments in the FTICR-MS, the protonated amino acids were generated by electrospray ionization (ESI) in a Micromass Z-spray source from approximately $1 \mathrm{mM}$ solutions of the sample in a solution of $1: 1$ acetonitrile:water containing $\sim 0.1 \%$ acetic acid. After the electrospray process, the ions were accumulated in a linear hexapole trap before being injected into the ICR cell. Fragment ions are generated by nozzle skimmer dissociation in the highpressure region at the interface of the electrospray source and the hexapole trap/accumulation region. A stored waveform inverse Fourier transform (SWIFT) [27] excitation pulse is used to isolate a single species in the cell. After irradiating the mass isolated ions for one or a few seconds with tunable infrared light (as described below), the mass spectrum of the ions which are left in the cell is recorded using an excite/detect procedure. The instrument and its typical operation has been described in detail elsewhere. [28]

For experiments in the Amazon ion trap MS, protonated amino acid ions were generated using ESI from $10^{-5}-10^{-6} \mathrm{M}$ solutions in 50:50 acetonitrile:water with $\sim 0.1 \%$ formic acid. The yield at each IR frequency is obtained from three averaged mass spectra. Isolated ions were subjected to CID conditions for $40 \mathrm{~ms}$ using an amplitude parameter of approximately 0.3-0.5 V. lons of interest were mass isolated and irradiated 1-4 pulses of tunable infrared light. A mass spectrum of the content of the trap is then obtained by scanning out the ion trap.

For both experiments, FELIX produced $6 \mu$ s long macropulses of approximately 20-60 mJ at a 5$\mathrm{Hz}$ repetition rate having a bandwidth of $\sim 0.5 \%$ of the center frequency. Absorption of infrared radiation increases the internal energy of the system which leads to frequency-dependent unimolecular dissociation. Relating parent and fragment ion intensities as the fragmentation yield $(\Sigma \mathrm{I}($ fragment ions $) / \Sigma \mathrm{I}($ parent + fragment ions $))$ and plotting the yield of each mass spectrum as a function of laser frequency generates an infrared vibrational spectrum. The yield is linearly corrected for the frequency dependent laser power and the infrared frequency is calibrated using a grating spectrometer.

\subsection{Computational Chemistry}

Density Functional Theory (DFT) calculations were performed at the B3LYP/6-31++G(d,p) level of theory using Gaussian09 revision D01 [29] to optimize the molecular geometries of the parent and fragment ions and to predict their (linear) IR spectra. Candidate input structures for 
these calculations were defined based on chemical intuition. The computed harmonic vibrational frequencies were scaled by 0.975 and convoluted with a $15 \mathrm{~cm}^{-1}$ full-width-at-halfmaximum Gaussian line shape to facilitate comparison with experimental spectra.

A Molecular Mechanics/Molecular Dynamics (MM/MD) approach using AMBER 12 [30] was applied to protonated glutamine and glutamine- $\mathrm{NH}_{3}$ in order to explore the potential energy surface and to find the lowest energy conformers. After minimization within AMBER, a simulated annealing procedure up to $1000 \mathrm{~K}$ was used. Guess geometries were first optimized in the Gaussian09 - revision D01 - package at the B3LYP/6-31++G(d,p) level of theory. 500 Structures were obtained in this procedure and grouped based on structural similarity using appropriate rms criteria to give 20-30 candidate structures. Next, these structures were each optimized at the B3LYP/6-31++G(d,p) level as described above. The frequencies were again scaled by 0.975 and convoluted with a $15 \mathrm{~cm}^{-1}$ full-width-at-half-maximum Gaussian line shape. All reported $298 \mathrm{~K}$ free energies are calculated using MP2(full)/6-311+G(2d,2p) electronic energies with the $\mathrm{B} 3 \mathrm{LYP} / 6-31++\mathrm{G}(\mathrm{d}, \mathrm{p})$ optimized structures and thermochemistry. The computational procedure is described in more detail in ref. [31].

\section{Results \& Discussion}

\subsection{Protonated asparagine $\left(\mathrm{AsnH}^{+}\right)$}

The IRMPD spectrum of the $\mathrm{AsnH}^{+}$precursor ion ( $\mathrm{m} / \mathrm{z}$ 133) has been recorded previously [32]. Comparison of the experimental spectrum with computed IR spectra for the three most stable conformers suggested that the amino acid is protonated at the $\mathrm{N}$-terminus.

The fragmentation pathways of $\mathrm{AsnH}^{+}$and $\mathrm{NaAsn}^{+}$, including the deamidation pathway, have also been investigated. [1,12] Two major routes for primary decomposition of $\mathrm{AsnH}^{+}$were established: loss of $\mathrm{NH}_{3}$ leading to an m/z 116 fragment and loss of $\mathrm{H}_{2} \mathrm{O}+\mathrm{CO}$ leading to an ion at $\mathrm{m} / \mathrm{z}$ 87. A fragment at $\mathrm{m} / \mathrm{z} 115$ (loss of $\mathrm{H}_{2} \mathrm{O}$ ) was also found and suggested to be a result of nucleophilic attack of the side-chain oxygen atom onto the $\mathrm{C}$-terminus. It was observed that the $\mathrm{m} / \mathrm{z} 116$ fragment dissociates further by loss of $\mathrm{O}=\mathrm{C}=\mathrm{CH}_{2}$, leading to a ${ }^{+} \mathrm{H}_{2} \mathrm{~N}=\mathrm{CH}-\mathrm{COOH}$ fragment 
( $\mathrm{m} / \mathrm{z}$ 74) and in parallel by loss of $\mathrm{CO}$ leading to ${ }^{+} \mathrm{H}_{2} \mathrm{~N}=\mathrm{CH}-\mathrm{CH}_{2}-\mathrm{COOH}$ at $\mathrm{m} / \mathrm{z} 88$. The $\mathrm{m} / \mathrm{z} 87$ fragment can lose an $\mathrm{HCN}$ molecule giving $\mathrm{H}_{3} \mathrm{~N}^{+}-\mathrm{C}(=0)-\mathrm{CH}_{3}$. Dookeran et al. [13] examined the fragmentation of $\mathrm{AsnH}^{+}$and $\mathrm{GlnH}^{+}$by energy-dependent $\mathrm{CID}$ using a $\mathrm{ZAB}-2 \mathrm{FQ}$ hybrid BEqQ mass spectrometer [33] by varying the collision gas. For $\mathrm{AsnH}^{+}$, low-energy metastable ion fragmentation was found to lead to dominant loss of $\mathrm{H}_{2} \mathrm{O}$ and $\mathrm{CO}$. At higher collision energies, loss of $\mathrm{NH}_{3}$ and further fragmentation by elimination of ketene becomes dominant, leading to a linear ${ }^{+} \mathrm{H}_{2} \mathrm{~N}=\mathrm{CH}-\mathrm{COOH}$ fragment with $\mathrm{m} / \mathrm{z}$ 74. Rogalewicz et al. [15] used a triple quadrupole mass spectrometer to examine the collision-induced dissociation of protonated $\alpha$-amino acids with Argon at $12 \mathrm{eV}$ lab energy (2.8 eV center of mass energy) under multiple collision conditions. From the estimated activation energy, the loss of $\mathrm{NH}_{3}$ was predicted to occur from the side chain protonated amide intermediate, which is favored over $\mathrm{NH}_{3}$ loss from the $\mathrm{N}$ terminus since that involves formation of a destabilizing carbocation. [15]

Here, the structure of the fragments generated from CID of $A_{s n H^{+}}$having m/z 116 and m/z 87 are examined using IRMPD ion spectroscopy. The intensity of the $\mathrm{m} / \mathrm{z} 115$ ion generated was too small for investigation. CID on the $\mathrm{m} / \mathrm{z} 116$ fragment resulted in m/z $88 \mathrm{~m} / \mathrm{z} 74$ and m/z 46 fragments.

\subsubsection{Fragment: $A s n H^{+}-\mathrm{NH}_{3}$}

Figure $1 \mathrm{~A}$ shows the experimental $I R$ spectrum of the mass-selected $\mathrm{m} / \mathrm{z} 116$ fragment ion along with the calculated spectrum for the lowest energy structure found (see table 1), the Nprotonated 3-amino succinic anhydride structure shown, indicated as (1) in Scheme 1A. This is the product ion structure identified in [12] based on threshold CID experiments and computation. The IR absorption band near $1820 \mathrm{~cm}^{-1}$ is assigned as the anti-symmetric combination of $\mathrm{C}=\mathrm{O}$ stretches in the succinic anhydride structure. The band around $1625 \mathrm{~cm}^{-1}$ can be assigned to $\mathrm{N}-\mathrm{H}$ bending, the band at $1480 \mathrm{~cm}^{-1}$ is assigned to $\mathrm{C}-\mathrm{H}$ bending and the lowintensity bands at 1433 and $1374 \mathrm{~cm}^{-1}$ are attributed to $\mathrm{CH}_{2}$ and $\mathrm{C}-\mathrm{H}$ bending modes, respectively.

The four-membered ring protonated $\beta$-lactam carboxylic acid structure (structure $\mathbf{5}$ in Scheme 1A) was suggested to be the result of a nucleophilic attack by the terminal amino nitrogen on 
the side chain amide carbon atom. [15] The relative free energy of this isomer is $+32 \mathrm{~kJ} / \mathrm{mol}$ compared to the succinic anhydride isomer, although protonation at the lactam carbonyl oxygen (4 in scheme $1 \mathrm{~A}$ ) reduces the relative free energy difference to $+26 \mathrm{~kJ} / \mathrm{mol}$. Nonetheless, the experimental IR bands around $1820 \mathrm{~cm}^{-1}$ and $1479 \mathrm{~cm}^{-1}$ are not well reproduced by the computed spectra for either of these lactam structures, as shown in Supporting Information Figure S1. The acylium ion structure reported in [13] is still higher in energy and can also be discarded based on the IR data. The calculated spectra of all structures in scheme $1 \mathrm{~A}$ are shown together with the experimental spectrum in the Supporting Information (Figure S1).

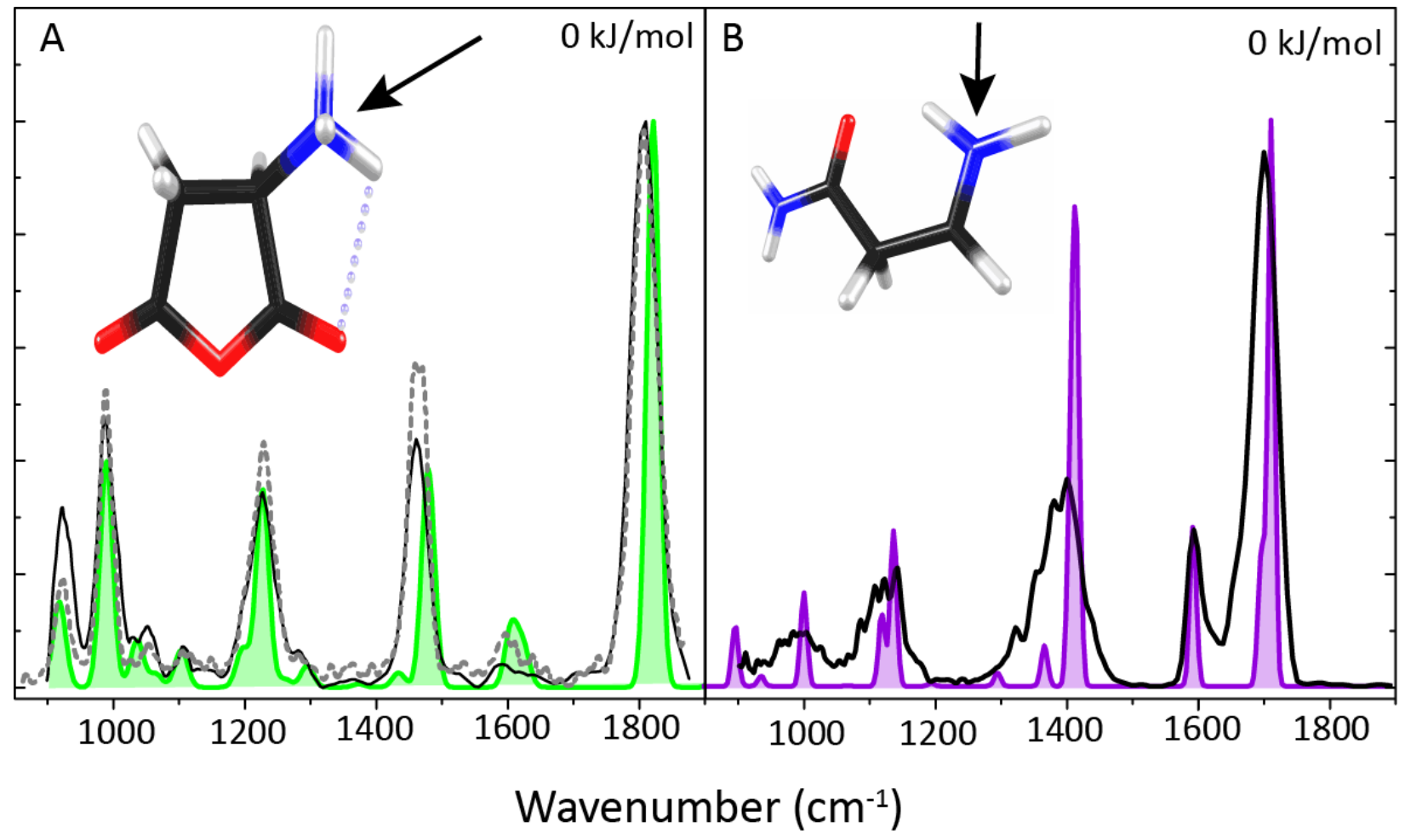

Figure 1: 
A. Experimental IRMPD spectrum of the $\mathrm{m} / \mathrm{z} 116$ fragment ion from protonated Asn (in black) and DFT calculated spectrum (green, as structure 1 in Scheme 1A)) of the 3-amino succinic anhydride structure proposed in [12]. The IRMPD spectrum of the $\mathrm{m} / \mathrm{z} 116$ fragment ion from protonated Asp is shown as the grey dotted line and is seen to have an identical spectrum. The arrow in the figure indicates the protonation site.

B. Experimental IRMPD spectrum of the $\mathrm{m} / \mathrm{z} 87$ product ion of $\mathrm{AsnH}^{+}$(in black) and calculated spectrum (purple, as structure 2 in Supporting Information Figure S2) of the iminium ion structure previously proposed in various reports. The arrow in the figure indicates the protonation site.

\subsubsection{Related: $\mathrm{H}_{2} \mathrm{O}$ loss from protonated aspartic acid $\left(\mathrm{AspH}^{+}\right)$}

Loss of water is a well-known fragmentation channel for protonated amino acids with a carboxylic acid group in their side chain (Asp and Glu). Elimination of $\mathrm{H}_{2} \mathrm{O}$ from protonated aspartic acid ( $\mathrm{m} / \mathrm{z} 134$ ) leads to an ion at $\mathrm{m} / \mathrm{z} 116$ and the reaction mechanism has been suggested to be analogous to $\mathrm{NH}_{3}$ loss from $\mathrm{AsnH}^{+}$, discussed above. Note that analogously to the suggested reaction pathways for protonated Asn, references [13,34] propose a linear acylium structure (not shown in figure $1 \mathrm{~A}$, see Supporting Info S1) for the ion produced by loss of $\mathrm{H}_{2} \mathrm{O}$ from protonated Asp.

Using IRMPD spectroscopy, it is now straightforward to verify whether the $\mathrm{m} / \mathrm{z} 116$ product ions from $\mathrm{AspH}^{+}$and $\mathrm{AsnH}^{+}$possess the same molecular structure. The IR spectrum (dashed grey trace) of $\mathrm{AspH}^{+}-\mathrm{H}_{2} \mathrm{O}$ is overlaid onto that of $\mathrm{AsnH}^{+}-\mathrm{NH}_{3}$ in figure $1 \mathrm{~A}$. In terms of band frequencies, it is clear that all bands are reproduced within the experimental accuracy. We hence conclude that the loss of $\mathrm{H}_{2} \mathrm{O}$ from protonated aspartic acid leads to an ion of the same structure as that of $\mathrm{AsnH}^{+}-\mathrm{NH}_{3}$, i.e. a 3-amino-succinic anhydride structure. This does not correspond to the structure proposed in refs. [13,34].

\subsubsection{Fragment: $A s n H^{+}-\left(\mathrm{CO}+\mathrm{H}_{2} \mathrm{O}\right)$}

In addition to deamidation, loss of $\mathrm{CO}+\mathrm{H}_{2} \mathrm{O}$ forms a major low-energy dissociation channel of $\mathrm{AsnH}^{+}$, leading to a product ion at $\mathrm{m} / \mathrm{z}$ 87. This dissociation pathway dominates over $\mathrm{NH}_{3}$ loss at 
the lowest collision energies. [13] Previous studies have explained this reaction pathway as being due to a proton transfer to the carboxyl group leading to sequential loss of $\mathrm{H}_{2} \mathrm{O}$ and $\mathrm{CO}$ from the C-terminus, leading to a product ion with an immonium ion structure. [12] The full potential energy surface for the reaction was reported in ref. [12].

Figure 1B shows the experimental spectrum of the $\mathrm{m} / \mathrm{z} 87$ fragment ion from $\mathrm{AsnH}^{+}$(blue trace) along with the calculated spectrum for the immonium ion structure, the protonation site is indicated with an arrow. In the calculated structure, the band at $1700 \mathrm{~cm}^{-1}$ is assigned to the imine bond stretching mode, the peak at $1597 \mathrm{~cm}^{-1}$ is attributed to an amide $\mathrm{NH}_{2}$ bending mode and the bands at $1371 \mathrm{~cm}^{-1}$ and $1123 \mathrm{~cm}^{-1}$ are $\mathrm{CH}_{2}$ bending modes. The match with the computed IR spectrum for the immonium ion structure is rather good. Alternative structures are conceivable, e.g. different protonation sites or structures resulting from cyclization through nucleophilic attack by the side-chain nitrogen or oxygen atoms onto the $\beta$-carbon leading to four-membered ring structures. However, as shown in the Supporting Information (Figure S2), these alternatives are substantially higher in energy and feature computed IR spectra that do not match the experimental data.

\subsubsection{Suggested Reaction Mechanism}

The identified product ion structures allow us to suggest the reaction mechanisms shown in Scheme 2 for the loss of $\mathrm{NH}_{3}$ and $\mathrm{H}_{2} \mathrm{O}+\mathrm{CO}$. Loss of $\mathrm{NH}_{3}$ occurs from the side chain amide by a nucleophilic attack of the C-terminal carbonyl oxygen, leading to a succinic anhydride structure. Loss of $\mathrm{CO}$ and $\mathrm{H}_{2} \mathrm{O}$ occurs by detachment of the protonated C-terminal carboxylic acid group leaving behind an immonium ion, in accordance with what has been suggested previously. [12] 


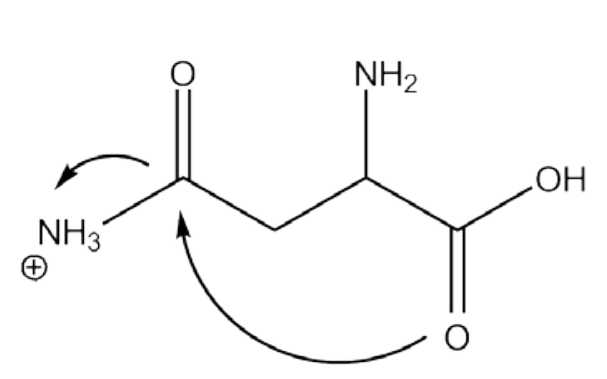

$\mathrm{m} / \mathrm{z}=133$

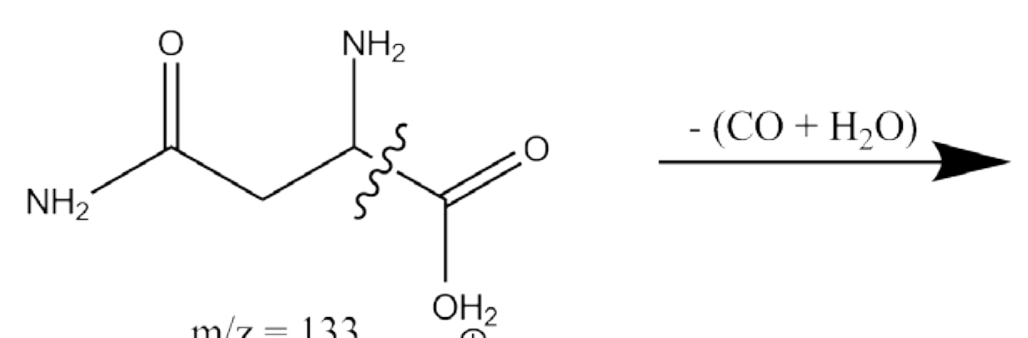

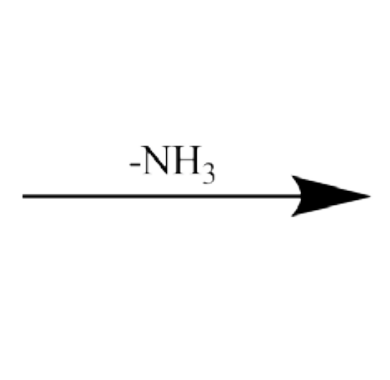

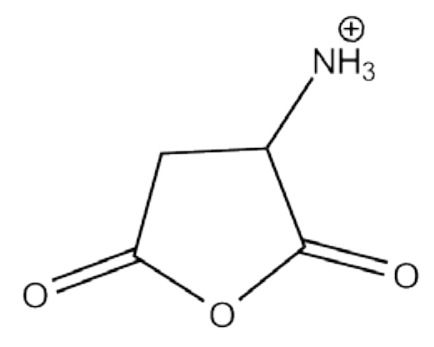

$\mathrm{m} / \mathrm{z}=116$

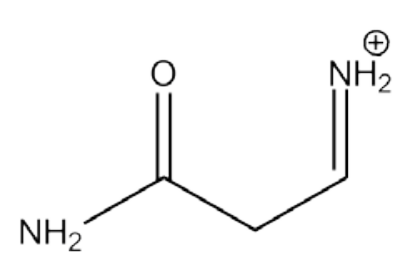

$\mathrm{m} / \mathrm{z}=87$

Scheme 2. Dissociation reaction mechanisms for $\mathrm{AsnH}^{+}$as suggested from spectroscopically identified product ion structures. 


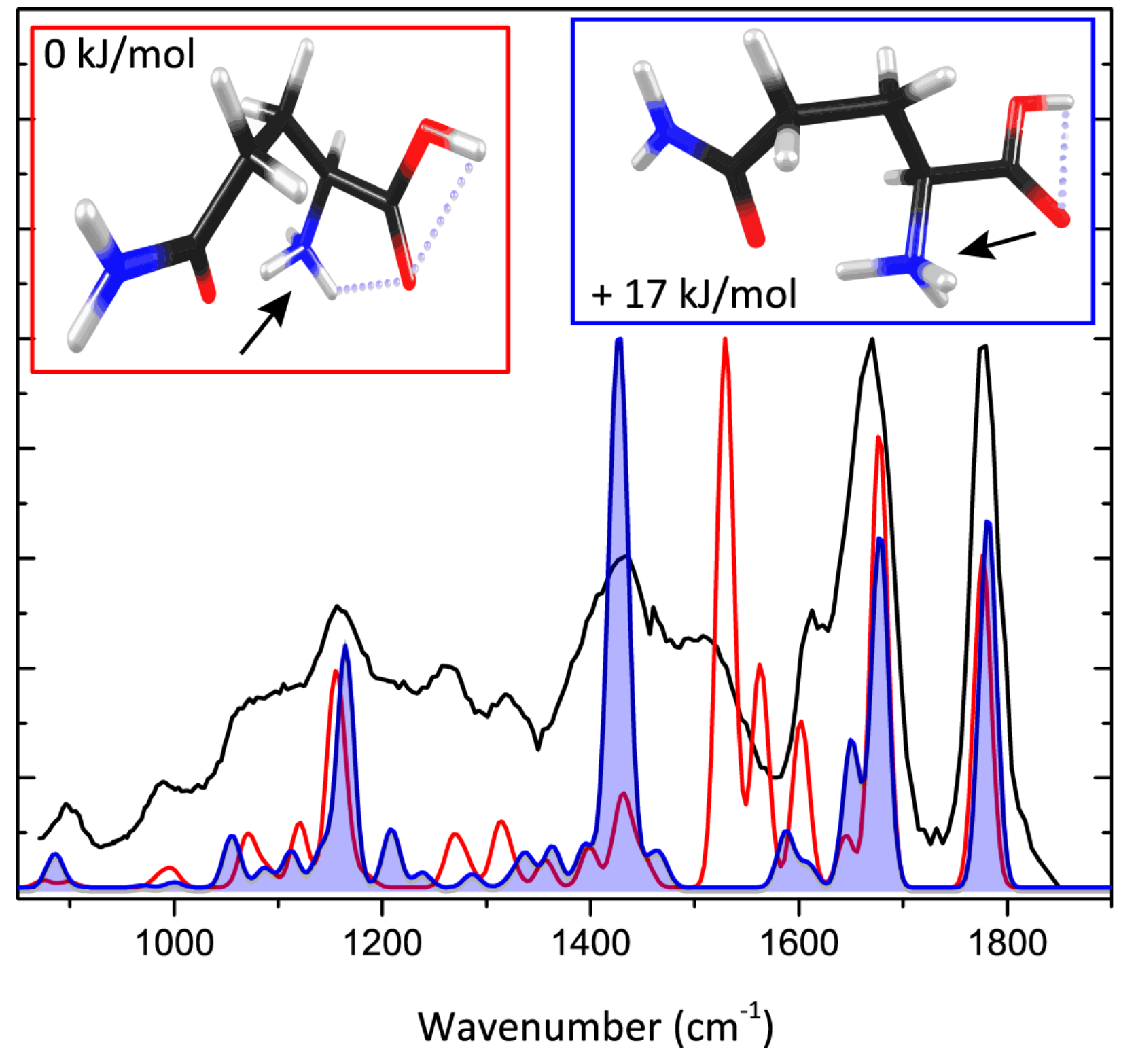

Figure 2. Experimental IRMPD spectrum of $\mathrm{GlnH}^{+}, \mathrm{m} / \mathrm{z} 147$ (black) compared with computed spectra for the lowest energy conformer (red) and an alternative conformer at $+17 \mathrm{~kJ} / \mathrm{mol}$ (blue). The two conformers differ only slightly in the orientation and $\mathrm{H}$-bonding of the protonated amino group. The higher energy conformer (blue shaded) appears to give the highest contribution to the experimental spectrum. This spectrum was measured in the FT-ICR MS. The arrows in the figure indicate the protonation site. 


\subsection{Protonated glutamine $\left(\mathrm{GlnH}^{+}\right)$}

To verify the molecular structure of $\mathrm{GlnH}^{+}(\mathrm{m} / \mathrm{z} 147)$ in the gas phase, its IRMPD spectrum has been recorded (see Figure 2). The experimental spectrum is compared to computed spectra for two conformers of the N-terminally protonated molecule. Despite their non-negligible computed relative free energy difference of $+17 \mathrm{~kJ} / \mathrm{mol}$, the experimental spectrum appears to match most closely to the calculated spectrum for the higher energy structure (blue shaded).

The main structural difference between the two conformers lies in the orientation of the protonated amino terminus relative to the carboxyl and carbonyl oxygen atoms. In the lowest energy conformer, one of the amino protons $\mathrm{H}$-bonds with the carbonyl oxygen and another one with the carboxyl oxygen. In the higher energy conformer, two protons H-bond with the carboxyl oxygen in a bifurcating fashion, while the third proton $\mathrm{H}$-bonds with the carbonyl oxygen; the $\mathrm{H}$-bonds in this conformer are significantly longer (1.6 and $2.4 \AA$ ) than in the lowest energy conformer (1.5 and $2.1 \AA$ ), indicating that the $\mathrm{H}$-bonds are weaker and likely explaining the higher relative energy. The diagnostic absorption band at $1429 \mathrm{~cm}^{-1}$ in the higher energy conformer corresponds to the bending mode of the $-\mathrm{NH}_{3}{ }^{+}$group. In the lowest energy conformer, the stronger $\mathrm{H}$-bonding stiffens this vibrational mode, shifting it up in frequency to about $1530 \mathrm{~cm}^{-1}$.

The two conformers have very similar structures and we expect that interconversion between them does not involve a significant barrier. It is therefore likely that a mixture of the two conformers exists and the spectrum appears to indicate this, particularly by the enhanced intensity in the $1400-1600 \mathrm{~cm}^{-1}$ range. Spectral broadening of IRMPD bands is not uncommon in cases where structures can dynamically interconvert $[35,36,37]$ and such a scenario is possibly at play here as well.

The other features in the spectrum are assigned as the $\mathrm{C}=\mathrm{O}$ stretch of the carboxylic acid group at $1781 \mathrm{~cm}^{-1}$, the amide carbonyl stretch at $1677 \mathrm{~cm}^{-1}$, modes having mainly $\mathrm{N}-\mathrm{H}$ bending character at 1651,1609 , and $1587 \mathrm{~cm}^{-1}$, and the $\mathrm{O}-\mathrm{H}$ bending mode of the carboxylic acid group at $1164 \mathrm{~cm}^{-1}$. 


\subsubsection{Fragment: $\mathrm{GlnH}^{+}-\mathrm{NH}_{3}$}

Various studies have reported that in contrast to $\mathrm{AsnH}^{+}$, elimination of $\mathrm{NH}_{3}$ is the only dominant low-energy dissociation pathway for $\mathrm{GlnH}^{+}$, which is confirmed in our experiments. Elimination of $\mathrm{NH}_{3}$ can conceivably occur from either the $\mathrm{N}$-terminus or the side-chain amide group (see Scheme 1B). Detachment of the N-terminal amine would lead either to 2-imino-5-carboxytetrahydrofuran (blue structure in scheme 1B) if cyclization occurs through the side-chain oxygen or to 2-pyrrolidone-5-carboxylic acid (also referred to as pyroglutamic acid or oxoproline) if cyclization occurs through the side-chain nitrogen (red structure in scheme 1B). Elimination of $\mathrm{NH}_{3}$ from the side-chain amide has been considered to be more likely, and will lead to the same oxo-proline structure (blue in scheme $1 \mathrm{~B}$ ) if cyclization occurs through the $\mathrm{N}$ terminal nitrogen. If cyclization occurs through the C-terminal carboxyl oxygen, a 3-aminoglutaric anhydride (green structure in scheme 1B) is formed. The latter reaction is analogous to that identified for $\mathrm{NH}_{3}$ loss from $\mathrm{AsnH}^{+}$, leading instead to the 5-membered succinic anhydride structure. The energies of these suggested structures are listed in Table 1.

Figure 3 shows the experimental IRMPD spectrum for the $m / z 130$ fragment corresponding to $\mathrm{GlnH}^{+}-\mathrm{NH}_{3}$ (black trace). The blue trace represents the vibrational spectrum predicted for the oxo-proline structure proposed in earlier studies. [13,38] Computed spectra for protonation on the lactam nitrogen ( 4 in scheme 1B) atom as well as on the oxo O-atom ( 5 in scheme 1B) are shown. In the calculated spectrum, the band at $1786 \mathrm{~cm}^{-1}$ is assigned to $C=0$ stretching of the carboxylic acid group, the absorption at $1687 \mathrm{~cm}^{-1}$ can be attributed to lactam $\mathrm{CN}$ stretching. The bands at $1480,1419,1276,1198$ and $1140 \mathrm{~cm}^{-1}$ have predominantly $\mathrm{C}-\mathrm{H}$ bending character. Changing the protonation site to the nitrogen atom (Figure $3 \mathrm{~B}$ ) yields a predicted spectrum that

does not match the experiment, as is most obvious from the bands at 1786 and $1687 \mathrm{~cm}^{-1}$. The relative free energy is $+29 \mathrm{~kJ} / \mathrm{mol}$ (see table 1 ).

To firmly establish the oxo-proline structure for $\mathrm{GlnH}^{+}-\mathrm{NH}_{3}$ (4 in scheme 1B) alternative structures were considered by comparing their predicted spectra to the experimental one. If the $\mathrm{NH}_{3}$-loss mechanisms for $\mathrm{AsnH}^{+}$and $\mathrm{GlnH}^{+}$were analogous, a six-membered amino-glutaric 
anhydride structure (structure 1 Scheme 1B) would have resulted for deamidation of $\mathrm{GlnH}^{+}$. The relative free energy of this structure is $60-100 \mathrm{~kJ} / \mathrm{mol}$ higher in energy (dependent on the protonation site, see table 1) than the oxo-proline structure. Calculated spectra for this structure do not match the experimentally observed IR spectrum, for instance, the experimental bands at 1786 and $1687 \mathrm{~cm}^{-1}$ are not reproduced in the calculated spectra (see Figure 3D). A final alternative is the substituted tetrahydrofuran structure resulting from elimination of the $\mathrm{N}$-terminal amine and concomitant cyclization through the side-chain oxygen atom (Figure 3C, 6 in scheme 1B). The relative free energy of this structure is only $+11 \mathrm{~kJ} / \mathrm{mol}$ than the oxo-proline structure. The calculated IR spectrum for this species, however, does not match as well as that for the O-protonated oxo-proline structure, especially considering the band at $1786 \mathrm{~cm}^{-1}$ and around $1100-1200 \mathrm{~cm}^{-1}$. From this we assign the the oxo-0-protonated oxo-proline structure as the product ion from deamidation of $\mathrm{GlnH}^{+}$. 


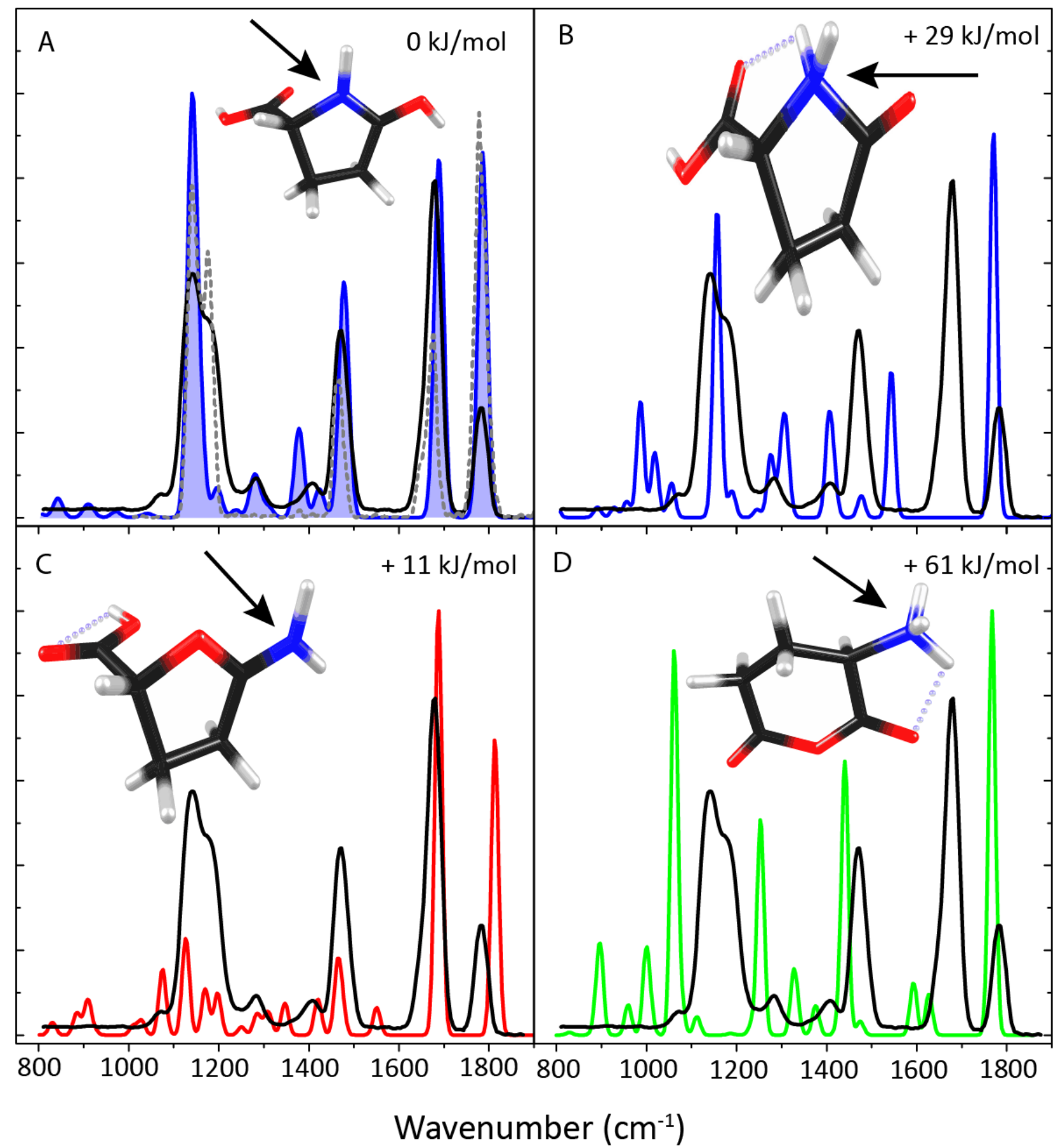

Figure 3. Experimental IRMPD spectrum of $\mathrm{GlnH}^{+}-\mathrm{NH}_{3}$ (black in all panels) compared with calculated spectra (colored according to the structures in Scheme 1B) for different isomeric structures for the $\mathrm{m} / \mathrm{z} 130$ ion. The best match is identified for the oxo-O protonated oxo-proline structure (top left, is the assigned calculation and therefore shaded). The dotted grey line represents the experimental spectrum for the $\mathrm{m} / \mathrm{z} 130$ fragment from $\mathrm{GluH}^{+}\left(\mathrm{H}_{2} \mathrm{O}\right.$ loss). The arrows indicate the protonation site of the structure. 


\section{Related: $\mathrm{H}_{2} \mathrm{O}$ loss from protonated glutamic acid ( $\mathrm{GluH}^{+}$)}

Protonated glutamic acid $\left(\mathrm{GluH}^{+}, \mathrm{m} / \mathrm{z}\right.$ 148) is similar to $\mathrm{GlnH}^{+}$except for a carboxylic acid group in the side chain replacing the amide group. Elimination of $\mathrm{H}_{2} \mathrm{O}$ from $\mathrm{GluH}^{+}$has been suggested $[13,38]$ to lead to the same product ion as that formed by $\mathrm{NH}_{3}$ loss from $\mathrm{GlnH}^{+}$. In order to verify this, the IRMPD spectrum of $\mathrm{GluH}^{+}-\mathrm{H}_{2} \mathrm{O}$ (grey trace) is overlaid onto the IRMPD spectrum of $\mathrm{GlnH}^{+}-\mathrm{NH}_{3}$ (blue trace) in Figure 3. Although the relative intensities of the bands show some deviations, attributed to differences in the experimental conditions, the band frequencies (1786, 1681, 1480 and $1140 \mathrm{~cm}^{-1}$ ) are reproduced closely, leading us to conclude that the product ions from $\mathrm{GluH}^{+}-\mathrm{H}_{2} \mathrm{O}$ and $\mathrm{GlnH}^{+}-\mathrm{NH}_{3}$ are the same.

\subsubsection{Fragment: $\mathrm{GlnH}^{+}-\mathrm{NH}_{3}-\left(\mathrm{H}_{2} \mathrm{O}+\mathrm{CO}\right)$}

In contrast to $\mathrm{AsnH}^{+}$, loss of $\mathrm{H}_{2} \mathrm{O}+\mathrm{CO}$ from $\mathrm{GlnH}^{+}$is not observed in parallel with deamidation. Instead, the $\mathrm{GlnH}^{+}-\mathrm{NH}_{3}$ fragment ion undergoes subsequent loss of $\mathrm{H}_{2} \mathrm{O}+\mathrm{CO}$ to arrive at a product ion at $\mathrm{m} / \mathrm{z} 84$. In [13] it is proposed that $\mathrm{CO}$ and $\mathrm{H}_{2} \mathrm{O}$ are formed from elimination of the carboxylic acid group from protonated oxo-proline leading to a pyrolidone-like structure shown in Figure 4. Based on deuterium labeling experiments, an alternative acyclic structure for the $\mathrm{m} / \mathrm{z} 84$ fragment ion from $\mathrm{GlnH}^{+}$and $\mathrm{GluH}^{+}$has also been suggested. [38] Computed spectra for both isomers are shown in Figure 4 along with the experimental IR spectrum for the $\mathrm{m} / \mathrm{z} 84$ fragment from $\mathrm{GlnH}^{+}-\mathrm{NH}_{3}$. We suspect that the small size of the molecule in combination with its rigidity causes the multiple-photon absorption and dissociation process to be relatively inefficient, so that weaker bands (especially at 1250 and $1050 \mathrm{~cm}^{-1}$ ) are not observed in the experimental IRMPD spectrum. 
The $\mathrm{m} / \mathrm{z} 84$ fragment is a result of the detachment of $\mathrm{CO}$ and $\mathrm{H}_{2} \mathrm{O}$ after loss of an $\mathrm{NH}_{3}$ from $\mathrm{GlnH}^{+}$. This is in contrast to the fragmentation mechanism of protonated asparagine, where the $\mathrm{m} / \mathrm{z} 87$ ion is formed directly from asparagine.

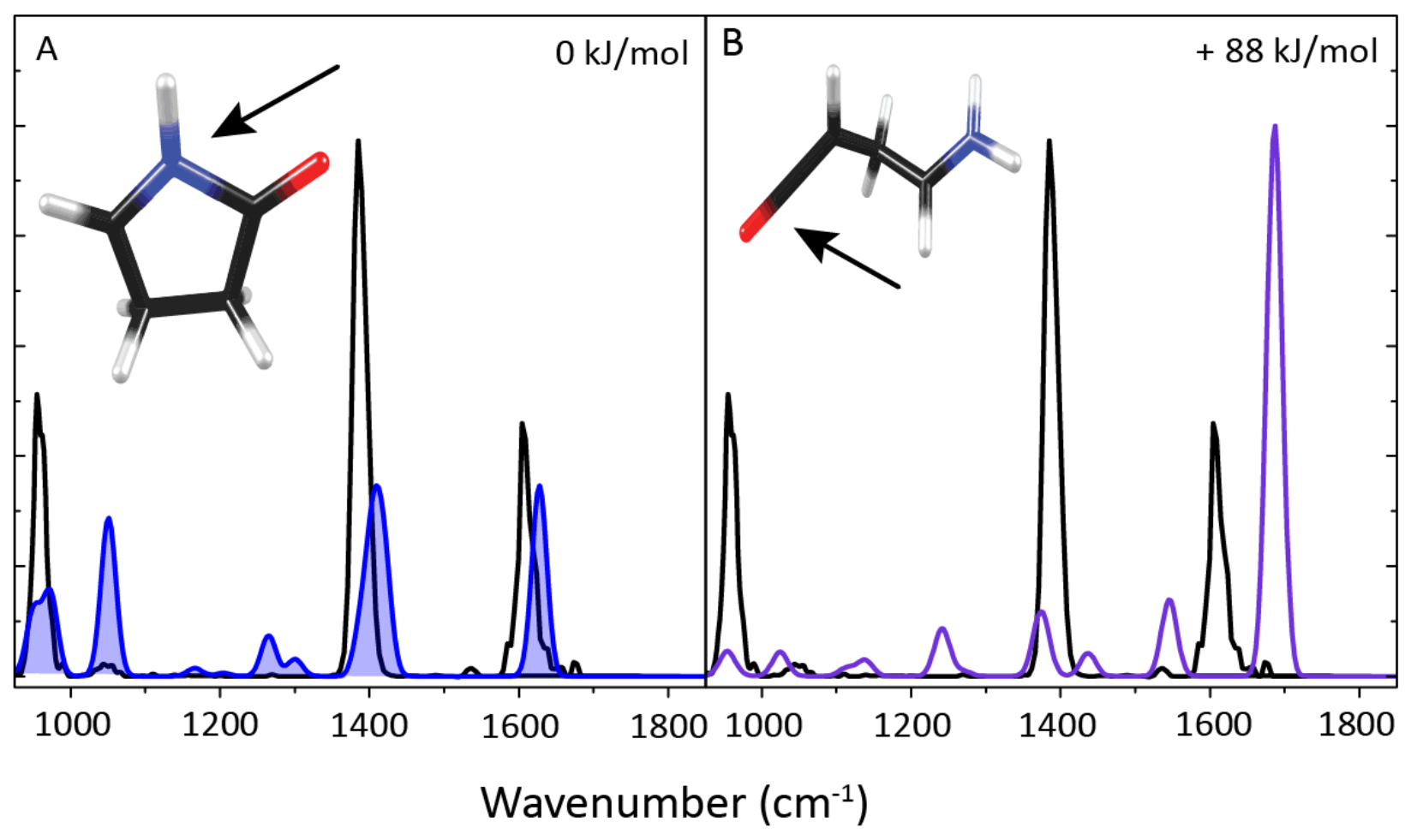

Figure 4. Experimental IRMPD spectrum of the $\mathrm{m} / \mathrm{z} 84$ fragment from $\mathrm{GlnH}^{+}-\mathrm{NH}_{3}$ (black) compared with calculated spectra for cyclic (A) (blue) and acyclic (B) (purple) isomers of this fragment. The cyclic pyrolidone-like structure is seen to provide the closest match to the experimental spectrum. The arrow indicates the protonation sites of the cyclic pyrolidone-like structure, for the acyclic structure, the arrow indicates the charged site.

Attributing the experimental structure to the cyclic isomer in Figure $4 \mathrm{~A}$, the peak at $1627 \mathrm{~cm}^{-1}$ is assigned to the $\mathrm{C}-\mathrm{N}$ stretching in the lactam. The peak around $1450 \mathrm{~cm}^{-1}$ is assigned to $\mathrm{C}-\mathrm{H}$ bending, the peaks at 1050 and $973 \mathrm{~cm}^{-1}$ to $\mathrm{C}-\mathrm{C}$ stretching.

The only other plausible alternative is the same pyrolidone-like structure with protonation at the oxygen instead of at the nitrogen, which gives a structure that is $57 \mathrm{~kJ} / \mathrm{mol}$ higher in energy. The computed spectrum for this protomer clearly disagrees with the experimental spectrum (as 
visible in Supporting Information Figure S3, so that we assign the structure in Figure 4A to the $\mathrm{m} / \mathrm{z} 84$ fragment ion.

\subsubsection{Suggested Reaction Mechanism}

From the identified structures in Figures 3 and 4, a suggested reaction mechanism can be derived, as presented in Scheme 3. Proton transfer from the $\mathrm{N}$-terminus to the side-chain amide nitrogen induces elimination of a neutral ammonia molecule with a concomitant nucleophilic attack of the $\mathrm{N}$-terminal nitrogen onto the carbonyl carbon of the side chain. This leads to an oxo-proline structure protonated on the oxo-oxygen atom. Further activation transfers the proton to the hydroxyl group of the carboxylic acid eliminating $\mathrm{H}_{2} \mathrm{O}+\mathrm{CO}$. This leaves behind a fragment ion at $\mathrm{m} / \mathrm{z} 84$ with a pyrolidone-like structure.

Admittedly, the identification of the structure of the $\mathrm{m} / \mathrm{z} 130$ ion does not distinguish between a reaction mechanism in which the ammonia molecule is eliminated from the $\mathrm{N}$-terminus or from the side-chain amide. Both reaction pathways lead to the same oxo-proline structure. Various reports have suggested $\mathrm{NH}_{3}$ to be eliminated from the side chain as it leads to an intermediate carbonium ion (at the side-chain carbonyl) rather than an intermediate carbocation (at the $\alpha$-carbon), which would occur upon $\mathrm{NH}_{3}$ loss from the $\mathrm{N}$-terminus and which is estimated to be less stable.

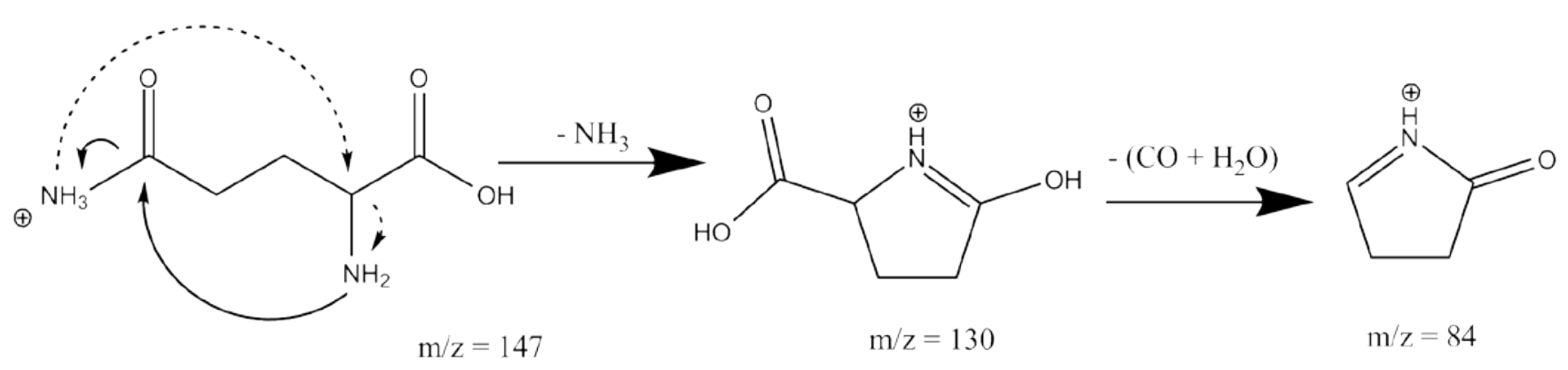

Scheme 3. The reaction mechanism (solid arrow) for the fragmentation of $\mathrm{GlnH}^{+}$as suggested from the product ion structures identified from their IRMPD spectra. The dashed arrow indicates an alternative mechanism leading to the same product ion structure. 


\section{Conclusion}

We have presented infrared spectra for CID products of $\mathrm{AsnH}^{+}$and $\mathrm{GlnH}^{+}$, including a comprehensive characterization of the product ions from the deamidation reactions. With the assistance of quantum-chemical computations, these spectra identify the product ion structures. AsnH ${ }^{+}-\mathrm{NH}_{3}$ is thus shown to possess a 3 -amino succinic anhydride structure protonated on the amino group, as had been suggested on the basis of measured and computed activation energies. The parallel dissociation reaction involving simultaneous loss of $\mathrm{H}_{2} \mathrm{O}$ and $\mathrm{CO}$ forms a linear immonium ion.

The infrared ion spectrum for the $\mathrm{NH}_{3}$-loss product from $\mathrm{GlnH}^{+}$establishes that a different reaction mechanism occurs for this species. While neutral ammonia is again eliminated from the side chain amide, the $\mathrm{N}$-terminal nitrogen now acts as the nucleophile leading to an oxoproline product ion structure. Both $\mathrm{AsnH}^{+}$and $\mathrm{GlnH}^{+}$thus form 5-membered ring structures upon deamidation. The fragmentation reactions for $\mathrm{H}_{2} \mathrm{O}$ loss from protonated aspartic and glutamic acid have also been spectroscopically investigated. These fragmentation reactions lead to structures that are identical to those found for the loss of $\mathrm{NH}_{3}$ from $\mathrm{AsnH}^{+}$and $\mathrm{GlnH}^{+}$.

\section{Acknowledgments}

The authors gratefully acknowledge the FELIX staff, particularly Dr. A.F.G. van der Meer and Dr. B. Redlich. Financial support for this project was provided by NWO Chemical Sciences under VICl project nr. 724.011.002. The authors also thank NWO Physical Sciences (EW) and the SARA Supercomputer Center for providing the computational resources. JO thanks the Stichting Physica. This work is part of the research program of FOM, which is financially supported by NWO. 


\section{References}

[1] A.L. Heaton, P.B. Armentrout, Thermodynamics and Mechanism of the Deamidation of Sodium-bound Asparagine. J. Am. Chem. Soc. 2008, 130, 10227.

[2] M. Orlowski, A.Meister, Enzymology of Pyrrolidone Carboxylic Acid, Academic Press, New York, 1971.

[3] P. Neta, Q. Pu, L. Kilpatrick, X. Yang, S. E. Stein, Dehydration versus deamination of NTerminal Glutamine in Collision-Induced Dissociation of Protonated Peptides. J. Am. Soc. Mass. Spectrom. 2007, 18, 27.

[4] E.B. Dunkelberger, L.E. Buchanan, P. Marek, P. Cao, D.P. Raleigh, M.T. Zanni, Deamidation Accelerates Amyloid Formation and Alters Amylin Fiber Structure, J. Am. Chem. Soc. 2012, 134, 12658.

[5] N.E. Robinson, A.B. Robinson, Molecular Clocks. PNAS, 2001, 98, 944.

[6] A. G. Harrison, T. Yalcin, Proton Mobility in Protonated Amino Acids and Peptides, Int. J. Mass Spectrom. And lon Processes, 1997, 165/166 339.

[7] S. Campbell, J.L. Beauchamp, M. Rempe, D.L. Lichtenberger. Correlations of lone pair ionization energies with proton affinities of amino acids and related compounds. Site specificity of protonation. Int. J. Mass Spectrom. Ion Processes, 1992, 117, 83.

[8] A.R. Dongre, J.L. Jones, A. Somogyi, V.H. Wysocki. Influence of Peptide composition, Gas-Phase Basicity, and Chemical Modification on Fragmentation Efficiency: Evidence for the Mobile Proton Model. J. Am. Chem. Soc. 1996, 118, 8365.

[9] V. H. Wysocki, G. Tsaprailis, L.L. Smith, L. A. Breci, Mobile and localized protons: a framework for understanding peptide dissociation. J. Mass Spectrom. 2000, 35, 1399.

[10] R. Boyd, A. Somogyi, The mobile proton hypothesis in fragmentation of protonated peptides: a perspective. J. Am. Soc. Mass Spectrom. 2010, 21, 1275.

[11] F. A. Konuklar, V. Aviyente, T. Z. Sen, I. Bahar, Modeling the deamidation of asparagine residues via succinimide intermediates. J. Mol. Model, 2001, 7, 147.

[12] A. L. Heaton, P.B. Armentrout, Thermodynamics and Mechanism of Protonated Asparagine Decomposition. J. Am. Soc. Mass Spectrom. 2009, 20, 852. 
[13] N. N. Dookeran, T. Yalcin, A. G. Harrison, Fragmentation Reactions of Protonated alphaamino acids. J. Mass Spectrom. 1996, 31, 500.

[14] A. G. Harrison, Fragmentation reactions of protonated peptides containing glutamine or glutamic acid. J. Mass Spectrom. 2003, 38, 174.

[15] F. Rogalewicz, Y. Hoppilliard, G. Ohanessian, Fragmentation Mechanisms of alpha-amino acids protonated under electrospray ionization. A Collision Activation and Ab Initio Theoretical Study. Int. J. Mass Spectrom. 2000 195/196, 565.

[16] J. Grzetic, J. Oomens, Spectroscopic Identification of Cyclic Imide b2-ions from peptides containing GIn and Asn Residues, J. Am. Soc. Mass Spectrom. 2013, 24, 1228.

[17] J. Grzetic. J. Oomens, Effect of the Asn side chain on the dissocation of deptronated peptides elucidated by IRMPD spectroscopy, Int. J. Mass Spectrom. 2013, 354-355, 70.

[18] B. Paizs, S. Suhai. Fragmentation Pathways of Protonated Peptides, Mass Spec. Rev. $2005,24,508$.

[19] S. Osburn, T. Burgie, G. Berden, J. Oomens, R. A. J. O'Hair, V. Ryzhov. Structure and Reactivity of Homocysteine Radical Cation in the Gas Phase Studied by Ion-Molecule Reactions and Infrared Multiple Photon Dissocation, J. Phys. Chem. A. 2013, 177, 1144.

[20] J. Oomens, J. D. Steill, B. Redlich. Gas-Phase IR Spectroscopy of deprotonated Amino Acids. J. Am. Chem. Soc. 2009, 131, 4310.

[21] C. F. Correia, P. O. Balaj, D. Scuderi, P. Maitre, G. Ohanessian, Vibrational Signatures of Protonated, Phosphorylated Amino Acids in the Gas Phase, J. Am. Chem. Soc. 2008, 131, 3359.

[22] R. Wu, T. B. McMahon, An Investigation of Protonated Sites and Conformations of Protonated Amino Acids by IRMPD Spectroscopy. ChemPhysChem 2008, 9, 2826.

[23] A. L. Patrick, C. N. Stedwell, B. Schindler, I. Compagnon, G. Berden, J. Oomens, N. C. Polfer, Insights into the fragmentation pathways of gas-phase protonated sulfoserine. Int. J. of Mass Spectrom. 2015, 379, 26. 
[24] J. Oomens, B. G. Sartakov, G. Meijer, G. von Helden, Gas-phase infrared multiple photon dissocation microscopy of mass-selected molecular ions, Int. J. of Mass Spectrom. 2006, $54,1$.

[25] D. Oepts, A.F.G.v.d. Meer and P.W. v. Amersfoort, The Free-Electron-Laser User Facility FELIX. Infrared Phys. Technol. 1995, 36, 297.

[26] J. J. Valle, J.R. Eyler, J. Oomens, D. T. Moore, A.F.G. van der Meer, G. von Helden, G. Meijer, C. L. Hendrickson, A. G. Marshall, G. T. Blakney , Free electron laser-fourier transform ion cyclotron resonance mass spectrometry facility for obtaining infrared multiphoton dissociation spectra of gaseous ions. Rev. Sci. Instrum. 2005, 76, 023103.

[2+] A.G. Marshall, T.C.L. Wang, T.L. Ricca, Tailored excitation for Fourier transform ion cyclotron mass spectrometry. J. Am. Chem. Soc. 1985, 107, 7893.

[28] N.C. Polfer, J. Oomens, Reaction products in mass spectrometry elucidated with infrared spectroscopy. Phys Chem Chem Phys, 2007, 9, 3804.

[29] M.J. Frisch, et al., Gaussian09, RevisionA.1, Gaussian, Inc., Wallingford, CT. 2009.

[30] D.A. Case TAD, T.E. Cheatham III, C.L. Simmerling, J. Wang, R.E. Duke, R. Luo, R.C. Walker, W. Zhang, K.M. Merz, B. Roberts, S. Hayik, A. Roitberg, G. Seabra, J. Swails, A.W. Goetz, I. Kolossváry, K.F.Wong, F. Paesani, J. Vanicek, R.M.Wolf, J. Liu, X. Wu, S.R. Brozell, T. Steinbrecher, H. Gohlke, Q.X. Cai Ye, J. Wang, M.-J. Hsieh, G. Cui, D.R. Roe, D.H. Mathews, M.G. Seetin, R. Salomon-Ferrer, C. Sagui, V. Babin, T. Luchko, S. Gusarov, A. Kovalenko, P.A. Kollman, AMBER, University of California, San Francisco, 2012.

[31] J.K. Martens, J. Grzetic, G. Berden, J. Oomens, Gas-phase conformations of small polyprolines and their fragment ions by IRMPD spectroscopy. Int. J. of Mass Spectrom. 2015, 377, 179.

[32] A.L. Heaton, V.N. Bowman, J. Oomens, J.D. Steil, P.B. Armentrout, Infrared Multiple Photon Dissociation Spectroscopy of Cationized Asparagine: Effects of Metal Cation Size on Gas-Phase Conformation. J. Phys. Chem. 2009, 113, 5519.

[33] A.G. Harrison, R. S. Mercer, E.J. Reiner, A. B. Young, R.K. Boyd, R. E. March and C. J. Porter, Ion Chemistry of Protonated Lysine Derivatives, Int. J. Mass Spectrom. Ion Processes. 1986, 74, 13. 
[34] A. G. Harrison, Y. Tu, Ion Chemistry of Protonated Aspartic Acid Derivatives, J. Mass Spectrom. 1998, 33, 532.

[35] M.K. Drayß, D. Blunk, J. Oomens, B. Gao, T. Wyttenbach, M. T. Bowers, M. Schäfer, Systematic Study of the Structures of Potassiated Tertiary Amino Acids: Salt Bridge Structures Dominate, J. Phys. Chem. A., 2009, 113, 9543.

[36] J. Oomens, J. D. Steill, B. Redlich, Gas-Phase IR Spectroscopy of Deprotonated Amino Acids, J. Am. Chem. Soc., 2009, 131, 4310.

[37] K.R. Asmis, N. L. Pivonka, G. Santambrogio, M. Brümmer, C. Kaposta, D. M. Neumark, L. Wöste, Science, 2003, 299, 1375.

[38] Harrison, A.G., Ion Chemistry of protonated glutamic acid derivatives. Int. J. of Mass Spectrom. 2001, 210/211, 361. 